Slavica

bruxellensia

\section{Slavica bruxellensia}

Revue polyphonique de littérature, culture et histoire

slaves

$1 \mid 2008$

Théâtre

\title{
Johan de Boose, Het geluk van Rusland. Reis naar het eenzaamste volk op aarde
}

\section{Eric Metz}

\section{OpenEdition}

\section{Journals}

Édition électronique

URL : http://journals.openedition.org/slavica/240

DOI : 10.4000/slavica.240

ISSN : 2034-6395

\section{Éditeur}

Université libre de Bruxelles - ULB

\section{Édition imprimée}

Pagination : 69-70

ISSN : 2031-7654

Référence électronique

Eric Metz, " Johan de Boose, Het geluk van Rusland. Reis naar het eenzaamste volk op aarde ", Slavica bruxellensia [En ligne], 1 | 2008, mis en ligne le 15 octobre 2008, consulté le 22 septembre 2020. URL http://journals.openedition.org/slavica/240 ; DOI : https://doi.org/10.4000/slavica.240

Ce document a été généré automatiquement le 22 septembre 2020

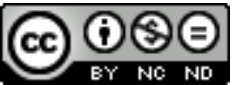

Les contenus de Slavica bruxellensia sont mis à disposition selon les termes de la Licence Creative Commons Attribution - Pas d'Utilisation Commerciale - Pas de Modification 3.0 France. 


\section{Johan de Boose, Het geluk van Rusland. Reis naar het eenzaamste volk op aarde}

Eric Metz

\section{RÉFÉRENCE}

Johan de Boose, Hetgeluk van Rusland. Reis naar het eenzaamste volk op aarde, Antwerpen/ Amsterdam, Meulenhoff-Manteau, 2008, 352 p. 
1 Ces dernières années Johan de Boose, slaviste, poète et romancier, a publié plusieurs livres retraçant ses expéditions en Europe centrale et orientale. Son dernier ouvrage, consacré à la Russie, peut être perçu comme l'apogée de ses récits de voyage. Il y dresse un bilan à la fois élaboré et très personnel de ses rencontres avec la Russie et ses habitants au cours des trois dernières décennies.

2 Het geluk van Rusland (Le bonheur de la Russie) appartient au genre du «voyage sentimental»: à l'opposé du guide touristique ou du récit historique, l'auteur n'hésite pas à présenter ses réflexions subjectives sur le pays qu'il découvre. Ils s'agit d'un voyage tant dans l'espace et le temps que dans l' "âme", celle de l'auteur comme celle du peuple qu'il décrit. L'analyse d'une psychologie

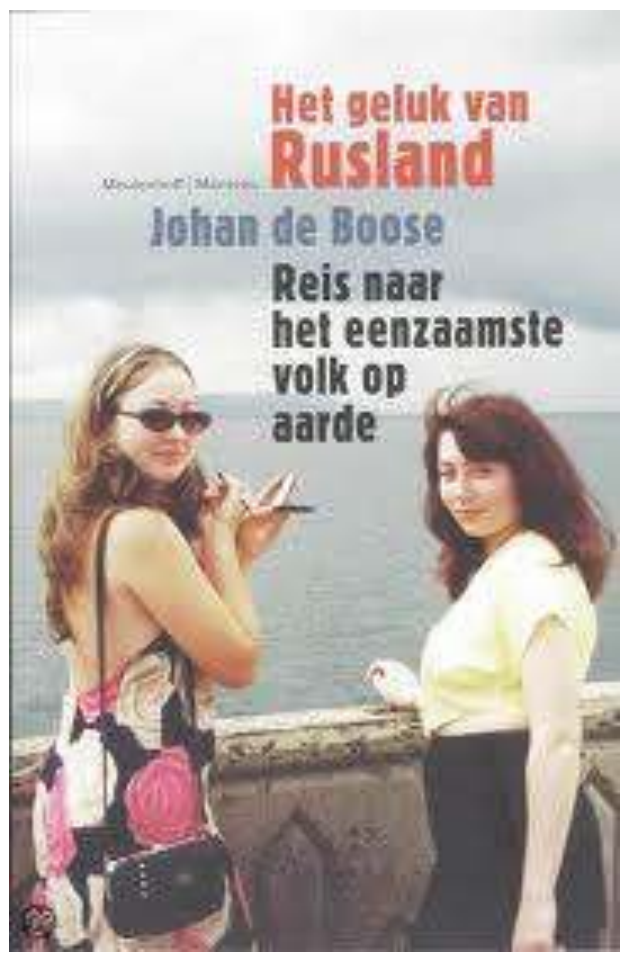
nationale supposée risque d'éveiller de vieux spectres imagologiques tels que celui de l' "âme slave ». Cependant, bien que son approche trahisse une certaine tendance essentialiste, de Boose se distancie d'emblée des préjugés existants, afin de trouver - comme il l'exprime - «les clés pour comprendre ce pays, pour accéder à son cœur ». Cette quête se nourrit de nombreuses conversations que l'auteur a tenues avec des Russes de tous âges et de toutes professions, de Moscou à Vladivostok, ainsi que de l'histoire et de la littérature russes. En puisant dans ses lectures du XIX ${ }^{\mathrm{e}}$ siècle et de l' « Âge d'argent » moderniste, l'auteur donne la parole aux écrivains d'antan pour commenter ce qu'il observe dans la Russie d'aujourd'hui. Ainsi, il se projette dans le Saint-Pétersbourg de 1911, et y rencontre Akhmatova et Mandel’štam dans un café littéraire.

Le livre comprend trois chapitres, consacrés respectivement à Moscou, SaintPétersbourg et la Sibérie. Le talent littéraire de de Boose imprègne tout le récit, qui est ingénieusement construit à la façon d'un texte romanesque - avec des rétrospections et des anticipations - offrant en même temps de magnifiques descriptions introspectives propres au poète lyrique. Si, par moments, le lecteur non initié peut être dérouté par l'alternance rapide d'écrivains et de personnages historiques, l'auteur convainc par ses considérations perspicaces - notamment sur "l'ostalgie », cette attirance paradoxale pour tout ce qui est soviétique, ressentie tant par des Russes que par des étrangers. 
INDEX

Index géographique : Russie

\section{AUTEURS}

\section{ERIC METZ}

Université de Gand (Belgique), Haute Ecole Artesis (Anvers, Belgique) ; membre du comité de rédaction de « Slavica Bruxellensia » 